\title{
MATERIAL EVALUATION AND NEED ANALYSIS IN SYLLABUS DESIGNING
}

\section{Mr. Shailendra H. Pandey}

The study draws insights to teacher and learners in terms of teaching material development. Teaching of the second language has been an important issue in modern world. It is not only an area of teaching but also an area of economic concerns. As a natural outcome that brings out, there is a hard competition among the publishers to obtain the high quality of the teaching materials. Any language learning process traditionally needs print materials or non-print materials (Reinders and White, 2010; Richards, 2001, p. 251; McGrath, 2002, pp. 125-136). The current paper is an assessment of the English Language curriculum that is taught in the colleges across Gujarat. Through this paper, it is focused on whether the curriculum fulfills learners' needs. Curriculum is used as a general term for the entire organized teaching plan of a subject. Syllabus refers to a pre-defined teacher and supervisor definition of how the curriculum will be accomplished over a predefined period. A curriculum can consist of a number of syllabi. In many parts of the world, language education programs are designed following a syllabus-driven approach, that is, the syllabus determines what kind of materials will be prescribed and in what ways they can be implemented for the classroom teaching. In certain educational contexts, the syllabus even determines how materials should be designed in the first place.

Key words: Material Evaluation, Syllabus Designing, Needs analysis,

\section{Introduction:}

The current paper is an assessment of the English Language curriculum that is taught in the colleges in Gujarat. Through this paper, it is focused on whether the curriculum fulfills learner's needs. Curriculum is used as a general term for the entire organized teaching plan of a subject. Syllabus refers to a pre-defined teacher and supervisor definition of how the curriculum will be 
accomplished over a predefined period. A curriculum can consist of a number of syllabi. In many parts of the world, language education programs are designed following a syllabus-driven approach, that is, the syllabus determines what kind of materials will be prescribed and in what ways they can be implemented for the classroom teaching. In certain educational contexts, the syllabus even determines how materials should be designed in the first place.

Material evaluation consists of establishing criteria for the curriculum and its match to the syllabus. Listed below are the syllabuses to be considered in the process of evaluation;

Grammatical syllabuses: The syllabus input is selected and graded according to grammatical notions of simplicity and complexity. These syllabuses introduce one item at a time and require mastery of that item before moving on to the next.

Lexical syllabuses: Lexical syllabuses identify a target vocabulary to be taught normally arranged according to levels such as the first 500, 1000, 1500, 2000 words.

Skills syllabuses: Skills syllabuses are organized around the different underlying abilities that are involved in using a language for purposes such as reading, writing, listening, or speaking.

Functional-notional syllabuses: In functional-notional syllabuses, the input is selected and graded according to the communicative functions (such as requesting, complaining, suggesting, and agreeing) that language learners need to perform at the end of the language program.

Content syllabuses: In content syllabuses, the content of language learning might be defined in terms of situations, topics, themes, or other academic or school subjects.

Task-based syllabuses: Task-based syllabuses are more concerned with the classroom processes which stimulate learning. These syllabuses consist of a list of specification of the tasks and activities that the learners will engage in class in the target language (Pakkan,1997; Brown, 1995; Harmer, 2001)

English language curriculum has witnessed substantial developments over the past decades. The process of curriculum development is a dynamic process involving interrelated elements of needs analysis, goals placement, implementation, and program evaluation (Richards, 2011). The evaluation of the existing curricula has been argued to have many benefits. According to Jackson (2005), curriculum evaluation is undertaken in order to ensure that the learners' needs are adequately addressed. The English for Academic Purposes (EAP) curriculum should undergo continuous evaluation and renewal in order to make it effective and responsive to the future needs of the learners. 
The needs assessment in an EAP is mainly carried out in order to obtain a deep insight and a greater input about the current and future needs of language learners from multiple perspectives: subject teachers, present and former students to assist in making well-advised decisions on the objectives and the goals that the new curriculum should address and to ensure that the curriculum content matches the students' needs as closely as possible (Cowling, 2007).

Textbook is regarded as the visible heart of any English language-teaching program. It is the foundation for how much linguistic input the students will get in the classroom (O’Neill, 2008). Richards (2011) argues that in some contexts, textbooks may provide the ground for the content of the lessons, and the type of linguistic practice the learners engage in. In other contexts, textbooks may be complementary to the teacher's instruction. For students, textbooks may be the main source of contact they have with the language apart from input given by the instructor (Cowling, 2007). Furthermore, textbooks may serve as a kind of training to the teachers by giving them ideas on how to teach lessons.

Besides being a fundamental teaching tool in regular English teaching and learning contexts, textbook also has a significant role in the process of innovation. According to Hutchinson and Torres (1994), the significance of the textbook becomes more vivid in periods of change. Textbooks may act as go-betweens and possible agents for change during educational innovation because of many reasons; first textbooks act as a tool for teacher and learner training, textbooks provide a picture of how the renewal will look like and they provide the psychological support to instructors.

Evaluation of the English language curriculum has become very common in all EFL contexts. This has coincided with the efforts of the educational authorities to produce native-like speakers of English in places where English is not the native language, has always been engaged in improving the English language teaching programs at all levels few years ago. This is an attempt to enhance these efforts by evaluating textbooks for the English Language.

\section{Research Questions:}

Following research questions guided the research;

a) To what extent does the textbook meet the needs of the learners?

b) What do the learners think of the textbook regarding its components?

c) What are the changes that should be made in the textbook in order to meet the needs of the learners? 


\section{Types of Syllabus Evaluation:}

Evaluation of syllabuses is an essential aspect in teaching English as a foreign language. According to Ellis (1997), there are two main types of evaluation: predictive and retrospective evaluation. Predictive evaluation is the assessment of course before implementation while retrospective evaluation takes place after the course is implemented. He argues that instructors often encounter the mission of selecting the materials that they will use. In other words, the teachers need to conduct a predicative evaluation of the materials that they have in hand in order to determine which materials suit their purposes the best. In addition, once they use these materials, they need to carry out further evaluation to identify whether these materials were workable or not. This is what is called the retrospective evaluation (Ellis, 1997: 36).

This paper is a kind of the retrospective evaluation. Since the textbooks are not produced by the EFL instructors themselves, the instructors have to determine which textbooks suit the needs of their learners. Accordingly, there are many textbooks produced around the world every year and this wide collection of textbooks is designed for EFL situations. This variation results in a confusion among teachers, particularly those who have not strong experience. In addition, experienced instructors may find it difficult to determine a textbook for their target students. As has been pointed out by Chambers (1997: 15), the materials selected in an English language teaching class should be chosen by the possible highest number of users. This is to enhance the feeling of decision ownership. Therefore, there is interrelatedness between the selection and evaluation of textbooks.

\section{Syllabus Evaluation Rationale}

Many reasons have been provided for textbook evaluation. Sheldon (1988) proposed that selection of an English language-teaching textbook often marks a significant a managerial and educational decision. Deep evaluation enables administrative and teaching staff of an organization to make a distinction between all available textbooks in the markets.

\section{ELT Syllabus Evaluation}

The studies that tackled the evaluation of textbooks in ELT context dealt with General English courses in the broader sense, textbook except for the teaching methods and some other sub-items. The results also revealed that although needs' assessment criterion such as; general appearance, design and illustration, topic appropriateness, skills development, and flexibility are satisfied in the book but still they need to be improved. 
General outcome of this study suggested that the materials have failed to provide students with an adequate source of interesting and academically purposeful substance to achieve the aims and objectives set for the students' learning process. The study also revealed that the Audio-Lingual approach, which is the underlying approach in teaching the materials, has been a factor in limiting the capabilities of accomplishing aims and objectives of learning the language. Textbooks reported that such textbooks should be modified in the light of students' gender, level, and needs.

The study tried to draw out the opinions of the teachers on the textbook regarding its components, its practicality, its activities, the language type, the subject, the content, and the four basic language skills incorporated in the book, the sub-skills of grammar and vocabulary, and how they are offered. It also investigated the appropriateness of the book regarding the learners' level and their needs. The results revealed that there was a consensus among the teachers on the suitability of the textbook. The results also revealed that the textbook corresponds to the teachers' expectations and meet the needs of the students.

Based on the above literature review, it is clear that the ELT syllabuses used in are related to the students' needs and meeting their due language level. Therefore, this adds to the previous efforts to evaluate the new project's textbook in the light of students' needs.

\section{Learners Needs}

While evaluation and developing materials it is impossible not to mention about the needs and variables of learners as the materials for learners' use. (Brown, 2000, p. 273) classified learner variables as: age, cognition, native language, input, affective domain and education background. Griffiths (2008) also lists a variety of variables such as;

Maturational factors: Critical/sensitive period, myelination,

Socio-affective factors: Culture/language shock, Social distance, anxiety, identity, disorientation, status,

Cognitive factors: Existing knowledge, strategic awareness, understanding of rule systems, metacognitive control,

Individual factors: Aptitude, attitude, gender, culture, personality, motivation, style, beliefs, prior learning, autonomy, personal circumstances,

Situational factors: Naturalistic, distance learning, classroom, daytime/night-time, teaching/learning, method, learning target, 
Towards Excellence: An Indexed, Refereed \& Peer Reviewed Journal of Higher Education / Mr. Shailendra Pandey / Page 128-134

In her learner variables study Griffiths (2008, p.261) visualized the preferred learning methods of the learners.

Moreover, "Some students want to learn English to improve career prospects in a specific area. They would probably regard a textbook on general English as a waste of time. Some want to qualify to enter foreign tertiary institutions. Material chosen for them would clearly be different from that chosen for beginners who want to learn English for pleasure. However theoretically 'correct,' material may be it will be unacceptable to students if it does not match their own goals" (Griffiths, 1995).

\section{Conclusion:}

Present research paper was an evaluation of the curriculum taught. This syllabus has been introduced, reflects the notion that the ELT syllabuses must undergo continuous evaluation in order to see whether these syllabuses meet the learners need or not. The learners' perceptions reveal that though learners are satisfied with the syllabus yet there are minor issues like; the difficulty of the material in the textbook, the allowing learners to interact in the classroom, and the number of the new vocabulary items in the textbook. Adding communicative exercises and activities such as group and pair work, games, puzzles and role-play as these can help learners carry out their communicative tasks in real life. Communicative approaches that can allow various activities are highly recommended. Only then, learner can be encouraged to talk and actually use the language. The attention should be on the performance and meaning rather than competence and accuracy.

\section{References}

Brown, H. D., Principles of Language Learning and Teaching: (4th Ed.). New York, NY., Pearson Education, 2000.

Brown, J. B., Textbook Evaluation Form: The Language Teacher 21.10, 15-21. 1997.

Chambers, F., Seeking Consensus in Textbook Evaluation: ELT Journal, 51(1). 1997.

Cowling, J., Needs Analysis: Planning a Syllabus for a Series of Intensive Workplace Courses at a Leading Japanese Company, English for Specific Purposes, 26, 426-442, 2007.

Ellis, R., The Empirical Evaluation of Teaching Materials: ELT Journal, 51 (1), 36-42. 1997.

Griffiths, C. Teaching/Learning Method and Good Language Learners: In Griffiths, C. (Ed). Lessons from Good Language Learners, (p.41) Cambridge, England, Cambridge University Press. 2008.

Griffiths, C., Evaluating Materials for Teaching English to Adult Speakers of Other Languages: English Teacher Forum, July, 50-51. 1995.

Hutchinson, T., Torres, E., The Textbook as Agent of Change: ELT Journal, 48, 4, 315-328, 1994. 
Jackson, J., An Inter-university, Cross-Disciplinary Analysis of Business Education: Perceptions of Business Faculty in Hong Kong, English for Specific Purposes, 24, 3, 293-306. 2005.

O’Neill, R., Why Use Textbooks?: ELT Journal, 36, 2, 104-111. 2008.

Pakkan, G., Language Teaching Materials Evaluation and Selection, Adaptation and Development: Istanbul: Surat, ELT. 1997.

Reinders, H., White, C., The Theory and Practice of Technology in Materials Development and Task Design: In Harwood, N. (ed.) English Language Teaching Materials, Theory and Practice. Cambridge, Cambridge University Press. 2010.

Richards, Jack C., Curriculum Development in Language Teaching: Cambridge, Cambridge University Press, 2011.

Sheldon, L. E., Evaluating ELT Textbooks and Materials: ELT Journal, 42(4), 237-246. 1988.

Mr. Shailendra H. Pandey

S. R. Bhabhor Arts College, Singvad, Dist. Dahod.

Email: shpandey11@gmail.com

Mobile No. 9099454005,9925783201 